\title{
ANTIFUNGAL EFFECT OF PHOTOCATALYTIC NANO -TITANIUM DIOXIDE INCORPORATED IN SILICONE ELASTOMER: (A MICROBIOLOGICAL STUDY)
}

\author{
Sarah Y. El Shafie ${ }^{* *}$ BDS, Ahmed M. El Shimy² PhD, Amel G. El Sheredy $P h D$, Maisa EL. \\ Moustafa ${ }^{4} P h D$.
}

ABSTRACT

INTRODUCTION: Titanium dioxide nanoparticles may improve the antifungal properties of silicone elastomer prosthetic materials. OBJECTIVES: To evaluate the photocatalytic antifungal activity of silicone elastomer incorporated with titanium dioxide nanoparticles against Candida albicans.

MATERIALS AND METHODS Titanium dioxide nano-particles (Aeroxide ${ }^{\circledR}$ TiO2 P25, Sigma Aldrich, USA) were characterized using xray diffraction analysis (XRD), scanning electron microscopy (SEM), transmission electron microscopy (TEM), uv-vis spectrophotometeric analysis, methylene blue degradation efficiency test and direct contact test. Sixty six disc shaped specimens ( 6 mm diameter x $1 \mathrm{~mm}$ thickness) of silicone elastomer (SE) (MED-4210, Factor II, USA) were included and divided into 6 groups based on the concentration of nano-TiO2 in silicone elastomer $(0 \%, 2 \%, 4 \%, 6 \%, 8 \%, 10 \%)(\mathrm{W} / \mathrm{W})$. Impregnated culture test was used to evaluate the antifungal activity of all SE samples against candida albicans as colonies forming units (CFUs) of treated aqueous suspension of candida albicans were measured at 0 , 30, 60, 90 and 120 min follow-up under UVA light. The dispersion of TiO2 within SE matrix was analysed by Laser scanning microscopy (LSM).

RESULTS: Data were analysed using ANOVA test and Tuckey's Post Hoc test. Nano-TiO2 characterization tests confirmed the crystalline structure (85\% anatase and 15\% rutile), shape (irregular faceted), size (22nm), absorption spectrum (320-400nm) and the photocatalytic antifungal ability of the as-purchased Aeroxide TiO2 P25. Planktonic cultures of candida albicans exposed to SE/TiO2 samples reduced candida albicans count by $4 \%$ - 99.99\%, depending on the nanoparticles concentration and follow-up time. The candida albicans counts did not decrease in group I without TiO2. LSM of SE specimens showed finer dispersion of TiO2 within SE matrix in group II, III and IV than that in group V and VI.

CONCLUSIONS: Incorporation of TiO2 P25 within SE (MED-4210) shows promising inhibitory activity against candida albicans. KEYWORDS: Antifungal activity, Candida albicans, photocatalytic nano-titanium dioxide, silicone elastomer.

1- Bachelor of Dentistry, Removable Prosthodontics Dentistry Department, Faculty of Dentistry, Alexandria University, Alexandria, Egypt.

2- Professor of Removable Prosthodontics, Head of Removable Prosthodontics Dentistry Department, Faculty of Dentistry, Alexandria University, Alexandria, Egypt.

3- Assistant Professor of Microbiology, Microbiology Department, Medical Research Institute, Alexandria University, Alexandria, Egypt.

4- Lecturer of Medical Biophysics, Medical Biophysics Department, Medical Research Institute, Alexandria University, Alexandria, Egypt.

Corresponding author:

E-mail: sarah.elshafie@yahoo.com.

\section{INTRODUCTION}

Patients suffering from facial defects caused by trauma, congenital abnormalities or ablative surgery are often provided with facial prostheses in order to mask the defect and to restore the patient's appearance when reconstructive surgery is not feasible $(1,2)$.

Silicone elastomer is the universal facial prosthetic material because of its unique physical, mechanical, and aesthetic properties (3). The challenging problem is susceptibility to colonization of complex microbial biofilm on these appliances. This may be attributed to hydrophobicity and surface roughness of silicone elastomer material which enhance biofilm formation (4). In addition, being used as facial appliances, the silicone elastomer are placed in contact with skin secretions and environmental factors (e.g., a dusty environment in a workshop) $(5,6)$. Furthermore, prosthesis-covered skin provides a unique niche for bacteria and yeast, which is caused by occlusion of the skin by the prosthesis resulting in increased humidity and temperature (2).
The presence of microbial biofilms colonized on surface of silicone facial prosthesis has several implications, importantly; their occurrence could be related to discoloration, degradation of physical and mechanical properties of silicone elastomer material and chronic infections in prosthesis skin contact area (7). This limits the mean longevity of the prostheses to 13 - 28 months. This limited longevity requires patients to make frequent hospital visits to replace the prosthesis, which is inconvenient to the patient and brings high costs to society $(8,9)$.

The prevention of biofilm formation on silicone facial prostheses is important in order to maintain the health of the soft tissue underneath the prosthesis and to preserve the prosthesis itself in a good condition. Mechanical and chemical cleaning methods often turns out to be inadequate especially when substrate surface is rough which hamper the complete removal of biofilm. In addition several other studies revealed that rigorous cleaning or the use of an inappropriate cleaning agent can lead to clinical problems 
such as deformation or surface degradation of the silicone elastomer $(10,11)$.

Therefore, several strategies have been proposed to improve cleaning guidelines for these prostheses or alternatively for new materials that are more resistant to microbial biofilm formation e.g., through incorporation of some biocompatible antimicrobial agents into silicone elastomer material itself (12). Some of antimicrobial agents used are associated with significant side-effects, including weak antimicrobial efficacy, risk of microbial resistance, difficulty in extending the antimicrobial functions (13). Thus, effective and long-term antimicrobial and biofilmpreventing materials constitute an immediate need. The use of nanoparticles has been suggested to incorporate antimicrobial activity into silicone elastomer materials. Among the available nanoparticles, titanium dioxide (TiO2) serves as a good example, because its antibacterial properties have been demonstrated in various biomaterials. Among dental prosthetic materials, Many studies were performed on the effect of nano-TiO2 in improving the antimicrobial properties of denture base resins and tissue conditioners $(14,15)$. However, only a few researches has been reported on the antimicrobial property of nano-TiO2 / silicone elastomer composite (16-18).

Titanium dioxide ( $\mathrm{TiO} 2)$ nanoparticles have attracted more attention as photocatalysts which produces free radicals on its surfaces by adequate light activation such as $\mathrm{OH}-$ and O2- that damage the bacterial cells (14). TiO2 shows wide, fast and sustaining antimicrobial capability against candida albicans, staphylococcus aureus, pseudomonas aeruginosa, escherichia coli, lactobacillus acidophilus, etc (19-22). And it has come to utilization as self-cleaning, antibacterial, and waste water purification component (23). Besides its antibacterial effects, $\mathrm{TiO} 2$ is chemically and physically stable and safe enough to be used as an additive for foods and cosmetics (24). Along with other characteristics such as white color, odour free and availability; it would be an appropriate substance that can be incorporated into the dental materials $(15,19)$. But the antimicrobial effect of nano-TiO2 which is of low utilization in visible light must be in the UV radiation $(18,21)$.

Interestingly, Candida species were exclusively cultivated from the skin underneath the facial prosthesis and were not detected on the healthy skin (2). Further studies suggested that the growth of Candida albicans on facial silicone elastomer materials, which is the most prevalent cause of fungal infections on the skin, may be more than that in other Candida species or other microorganisms, so we included them in our study (25). Hence, this study was conducted for evaluating the antifungal activity of silicone elastomer containing $\mathrm{TiO} 2$ nanoparticles against Candida albicans.

\section{MATERIALS AND METHODS}

\section{Study design:}

Titanium dioxide nano-Particles were characterized using x-ray diffraction analysis (XRD), scanning electron microscopy (SEM), transmission electron microscopy (TEM), uv-vis spectrophotometeric analysis, methylene blue degradation efficiency test and direct contact test. A total of 66 disc - shaped specimens (6 mm in diameter $\mathrm{x} 1$ $\mathrm{mm}$ in thickness) were prepared by combining the silicone elastomer with various weight percentages of the $\mathrm{TiO}_{2}$ nanoparticles. All the $\mathrm{SE} / \mathrm{TiO}_{2}$ specimens were further evaluated by microbiological experiments to assess the photocatalytic antifungal effect against candida albicans.

\section{Materials}

The two-component silicone elastomer (MED-4210) were supplied by the Factor II Inc., USA. The elastomeric component of MED-4210 comprises a dimethylsiloxane polymer, reinforcing silica, and a platinum catalyst. The curing agent component comprises a dimethylsiloxane polymer, an inhibitor, and a silicone cross-linker. The $\mathrm{TiO}_{2}$ nanoparticles (Aeroxide ${ }^{\circledR} \mathrm{TiO}_{2}$ P25) were purchased form Sigma Aldrich Inc., USA. $\mathrm{TiO}_{2}$ composed of anatase (85\%) and rutile $(15 \%)$ crystal structure with the mean diameter of the Nano- $\mathrm{TiO}_{2}$ particles is $21 \mathrm{~nm}$ according to the manufacturer. Candida albicans fungal strain were bought from the cell Bank of the Microbiological department of the Medical Research Institute (Alexandria University).

\section{Characterization of $\mathrm{TiO}_{2}$ Nanoparticles:}

\section{Morphological Characterization:}

We characterized the $\mathrm{TiO}_{2}$ nanoparticles by scanning electron microscope and transmission electron microscope analyzing the surface morphology of $\mathrm{TiO}_{2}$ nanoparticles in terms of particle size and shape. Scanning electron microscopy investigations was carried out using (SEM, JSM-6010LV, Jeol Inc., USA), samples of $\mathrm{TiO}_{2} \mathrm{NPs}_{\text {were }}$ placed on a metal plate and adhere using silver, The samples were coated with a thin platinum-palladium layer using coater (Auto Fine Coater JEC-3000FC, Jeol Inc., Japan) Samples were then observed at $\mathrm{x} 10.000$ and $\mathrm{x} 15.000$ magnification and at accelerating voltage of $20 \mathrm{KV}$. Transmission electron microscopy investigations was carried out using (TEM, JEM-2100F, Jeol Inc., USA). The particle suspension was diluted 10 times with ethanol and deposited drop-wise onto a 400-mesh copper grid coated with carbon film, and were allowed to dry in the air before studying by microscope.

\section{XRD Analysis:}

$\mathrm{X}$-ray diffraction powder patterns were used to determine the crystalline structure were recorded on an X-ray diffractometer (Lab-X-6100, Shimadzu Co., Japan). Analysis was done using monochromatized $\mathrm{Cu} \mathrm{K} \alpha$ radiation with a scan step of 0.02 degree/second and $2 \theta$ degree value of 20 -70 degrees. The voltage and current used were $30 \mathrm{kV}$ and $30 \mathrm{~mA}$, respectively. The peak patterns and values obtained were compared with the standard patterns and values.

\section{Spectroscopic Characterization:}

Solid-state UV absorption spectra range were measured in a UV-Vis spectrophotometer (U-3900, Hitachi Co., Japan) recorded at $25^{\circ} \mathrm{C}$ in the $200-900 \mathrm{~nm}$ spectral region.

Methylene Blue dye degradation efficiency (26):

The photocatalytic activity of $\mathrm{TiO}_{2} \mathrm{P} 25$ was evaluated by the photocatalytic degradation of methylene blue (MB) dye that was performed in a $250 \mathrm{~mL}$ cylindrical glass beaker containing $100 \mathrm{~mL}$ of $\mathrm{MB}$ solution (2\%) and $0.05 \mathrm{~g}$ of the $\mathrm{TiO}_{2}$ photocatalyst measured by electronic balance (JC320AB, Taiwan HUAKE Co., China). After that, the solution was irradiated with UV light produced by an ultraviolet lamp (UV-A, highest emission at $368 \mathrm{~nm}$ ) with 15 W black-light (F15W-T5-BL, Sylvania, Germany) positioned $10 \mathrm{~cm}$ above the surface of reaction solution. Aliquots of $3 \mathrm{~mL}$ were collected every $15 \mathrm{~min}$ in a period of 
$1 \mathrm{~h}$, then were centrifuged (ROTOFIX 32 A, Hettich Co., $\mathrm{UK}$ ) at $4000 \mathrm{rpm}$ for $3 \mathrm{~min}$ and the supernatant was analysed in a UV-vis spectrophotometer (Microlab 300, ELITech Group B.V., The Netherlands, Europe) to record the absorption band maximum $(620 \mathrm{~nm})$ of $\mathrm{MB}$ as a function of the time; the concentration of $\mathrm{MB}$ is proportional to the maximum absorbance at $620 \mathrm{~nm}$. Optical density of $\mathrm{MB}$ solution without addition of $\mathrm{TiO}_{2}$ nanoparticles measured in the dark was considered the control group. The experiment was repeated three times and the average computed.

\section{Evaluation of Photocatalytic Antifungal Activity of $\mathrm{TiO}_{2}$} P25:

\section{Fungal Culture and Media Preparation}

The growth medium, Nutrient broth (NB), was prepared from $1 \mathrm{~g}$ beef extract, $2 \mathrm{~g}$ Yeast extract, $5 \mathrm{~g}$ Peptone, $5 \mathrm{~g}$ Sodium chloride $(\mathrm{NaCl})$ in $1.00 \mathrm{~L}$ of sterilized distilled water (SD $\mathrm{H}_{2} 0$ ). Sabourauds dextrose agar (SDA) was prepared in the same manner from $10.0 \mathrm{~g}$ of mycological peptone, $40.0 \mathrm{~g}$ of dextrose $15.0 \mathrm{~g}$ of agar. The mixtures were then boiled for $1 \mathrm{~min}$, then autoclaved at $121^{\circ} \mathrm{C}$ for 15 min, and then cooled to 45 to $50^{\circ} \mathrm{C}$ and poured into sterile tubes or petri dishes respectively.

\section{Preparation of Standard Candidal Suspension :}

Candida albicans was inoculated in a SDA medium with a sterile inoculating loop in order to obtain isolated colonies, and then the plates were incubated aerobically at $37^{\circ} \mathrm{C}$ for $24 \mathrm{~h}$ in an inverted position (agar side up). One colony of the culture strain was taken and was inoculated into $3 \mathrm{ml}$ of NB. After overnight culture, the turbidity of the cells was adjusted to 0.5 MFC (McFarland turbidity). Then, the yeast was readjusted to required final concentration between $1.0 \times 10^{5}$ to $2.0 \times 10^{5} \mathrm{CFU} / \mathrm{ml}$ by serial dilution (with $\mathrm{SD}$ $\mathrm{H}_{2} \mathrm{O}$ ). Then, $10 \mathrm{ul}$ of the direct, $10^{2}, 10^{4}, 10^{6}$ dilutions were plated on SDA plates using the spread plate method and incubated at $37^{\circ} \mathrm{C}$ for $24 \mathrm{~h}$ and the colonies counted.

\section{Direct contact method (27):}

The photocatalytic treatment of prepared water suspension of $\mathrm{C}$. albicans were carried out with $0.5 \mathrm{mg}$ of $\mathrm{TiO}_{2} \mathrm{P} 25$ per ml. $\mathrm{TiO}_{2}$ treated suspension was then poured in sterile cylindrical glass beakers $(50 \mathrm{ml})$. The experiment was conducted under UV-A light lamp (highest emission at 368 $\mathrm{nm}$ ) (F15W-T5-BL, Sylvania, Germany) positioned $10 \mathrm{~cm}$ above the surface of reaction solution. For the treatment, 2 $\mathrm{ml}$ of the suspension was draws by using a sterile plastic syringe after $0,30,60,90$, and $120 \mathrm{~min}$, then the treatments samples were centrifuged (ROTOFIX 32 A, Hettich Co., $\mathrm{UK})$ at $4000 \mathrm{rpm}$ for $3 \mathrm{~min}$ to separate the solid catalyst, $100 \mathrm{ul}$ of supernatants immediately added into sterile wells of 96-well microtiter plate using sterile pipette tips and was analysed in a microplate reader (Infinite F50, Tecan Group, Switzerland, Europe) at $450 \mathrm{~nm}$ to record the absorption band maximum of viable candida cells as a function of the time; the number of viable cells are proportional to the maximum absorbance at $450 \mathrm{~nm}$. Then, 10 ul of the supernatants were also plated on SDA plates using the spread plate method and incubated at $37^{\circ} \mathrm{C}$ for $24 \mathrm{~h}$ and the colonies forming units (CFUs) for each plate were counted. Optical density of candida albicans solution without addition of $\mathrm{TiO}_{2}$ nanoparticles measured in the dark was considered the control group. The experiment was repeated three times and the average computed. The effect of UVA alone on candida was also measured.

\section{Pilot study}

A pilot study was performed to assess the antifungal activity of $2 \%, 4 \%, 6 \%, 8 \%$ and $10 \%(\mathrm{w} / \mathrm{w})$ of $\mathrm{TiO}_{2}$ in silicone elastomer, using methodology described below. Since comparable antifungal activity against candida albicans was seen in different weight percentage, 6 wt $\%$ of $\mathrm{TiO}_{2}$ nanoparticles was considered, for economic reasons to the end user and less effect on the mechanical properties of silicone elastomer.

\section{Specimens Preparation (28):}

The test samples were composed of $0 \%, 2 \%, 4 \%, 6 \%, 8 \%$, or $10 \%(w / w)$ proportions of $\mathrm{TiO}_{2}$ nanoparticles and the silicone elastomer base and curing agent mass ratio of $(10: 1)$ as recommended by the manufacturer. Components were weighted by the electronic balance (JC-320AB, Taiwan HUAKE Co., China). Subsequently, The $\mathrm{TiO}_{2}$ nanoparticles were added proportionately to silicone elastomer base and stirred to form a homogenous mixture, using mechanical stirrer (OST 20, IKA, USA) in clean glass beakers (250 ml each) with mixing speed 150-200 rpm for $10 \mathrm{~min}$. Then, silicone elastomer curing agent were added to the mixture in the recommended ratio and the components were mixed for another $10 \mathrm{~min}$ by the mechanical stirrer at the same mixing speed. The air bubbles in the mixture were eliminated with incubation for $30 \mathrm{~min}$ in a vacuum oven (LabStrong OVL-578-090G, Fi-Streem, UK). Subsequently, the mixture was loaded into prefabricated split copper molds lined with petroleum jelly. The samples were stored at $23^{0} \mathrm{C}$ for $24 \mathrm{~h}$ for curing. After which the molds were carefully separated, specimens removed and flashes trimmed away by using a scalpel and a sterile scissor. Specimens then had been washed 3 times with hand soap, carefully washed with demineralized water, and sterilized by autoclave $\left(121^{\circ} \mathrm{C}, 15 \mathrm{~min}\right)$. Blank silicone elastomer with no $\mathrm{TiO}_{2}$ served as the control group.

\section{Grouping}

Group I: Silicone elastomer containing 0 wt \% of $\mathrm{TiO}_{2}$ nano-particles.

Group II: Silicone elastomer containing 2 wt $\%$ of $\mathrm{TiO}_{2}$ nano-particles.

Group III: Silicone elastomer containing 4 wt \% of $\mathrm{TiO}_{2}$ nano-particles.

Group IV: Silicone elastomer containing 6 wt \% of $\mathrm{TiO}_{2}$ nano-particles.

Group V: Silicone elastomer containing 8 wt \% of $\mathrm{TiO}_{2}$ nano-particles.

Group VI: Silicone elastomer containing 10 wt \% of $\mathrm{TiO}_{2}$ nano-particles.

\section{Specimens testing:}

\section{Laser scanning microscopy (LSM):}

Six disc shaped silicone elastomer specimens $(6 \mathrm{~mm}$ diameter x $1 \mathrm{~mm}$ width) $(\mathrm{N}=6, \mathrm{n}=1)$ were prepared using prefabricated split disc shaped copper molds. A laser microscopic examination was performed to monitor the degree of dispersion of titanium dioxide nanoparticles within the silicone elastomer matrix using a laser scanning confocal microscope (VK-X100 Keyence, California, USA) Specimens were observed at x10.000 magnification.

\section{Microbiological testing:}

Silicone elastomer / $\mathrm{TiO}_{2}$ specimens were evaluated for its antifungal activity against candida albicans using microbiological experiments under exposure to UVA light. 


\section{Quantitative assessment by impregnated culture method (18):}

sixty - disc shaped silicone elastomer specimens $(6 \mathrm{~mm}$ diameter x $1 \mathrm{~mm}$ width) $(\mathrm{N}=60, \mathrm{n}=10)$ were prepared as mentioned and used in this experiment. The photocatalytic treatment of as prepared water suspension of C. albicans $\left(1.0 \times 10^{5}\right.$ to $\left.2.0 \times 10^{5}\right)$ were carried out with $\mathrm{TiO}_{2} \mathrm{P} 25$ incorporated in silicone elastomer discs. The sterile silicone elastomer disc specimens in all six groups were individually soaked in 6 wells of sterile 96-well microtiter culture plate containing 100 ul of prepared candida suspension in each. The experiment was conducted under UV-A light positioned $10 \mathrm{~cm}$ above the surface of reaction plate. $10 \mathrm{ul}$ of candida suspension was drawn from each well every 30 min in a period of $2 \mathrm{~h}$ and then plated on SDA plates using spread plate method and incubated at $37^{\circ} \mathrm{C}$ for $24 \mathrm{~h}$ and the colonies forming units for each plate were counted. For the control group specimens, the same steps were repeated, but without exposure to UVA light to eliminate the killing effect of UVA on candida cells. The experiment was repeated and the average computed. The percents of candida albicans CFUs reduction were calculated.

\section{Statistical analysis:}

The collected data was fed to statistical software IBM SPSS version 20 . Quantitative normally distributed data were described using mean and standard deviation as well as, minimum and maximum. All statistical analysis was done using one-way analysis of variance (ANOVA). Tuckey's post hoc test was used to determine differences between any of the groups, with a significance level of $\mathrm{P}<0.05$.

\section{RESULTS}

\section{Characterization of $\mathrm{TiO}_{2}$ photocatalyst: \\ Morphological characterization}

From the patterns obtained SEM micrographs, an irregular particle shape was observed in (Fig.1).

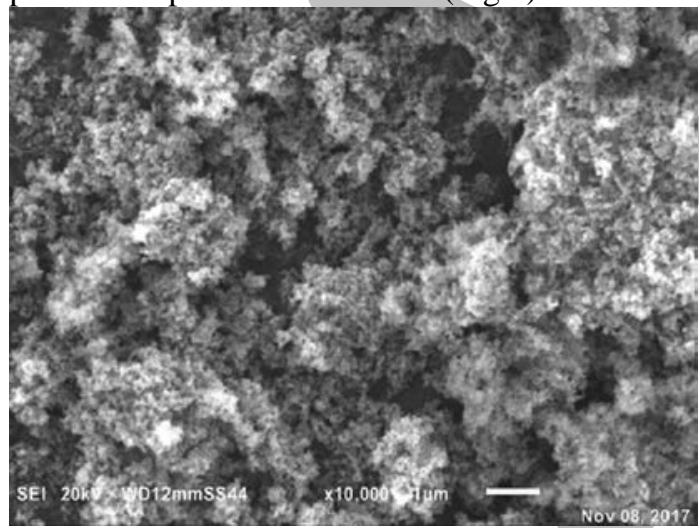

Figure 1: showing SEM of Aeroxide ${ }^{\circledR} \mathrm{TiO} 2 \mathrm{P} 25$ nanoparticles at x10.000 Magnification

TEM image reported in (Fig.2) show that the P-25 nanoparticles used in this study present an irregular faceted morphology and an average diameter size of about $22 \mathrm{~nm}$.

\section{XRD Analysis}

From the elaboration of the XRD pattern of the P-25 photocatalyst (Fig.3), it was observed that the patterns of aspurchased material matched the standard and it showed that $\mathrm{TiO}_{2}$ was characterized by two main crystalline structures: $85 \%$ of anatase phase, and for the remaining, $15 \%$ of rutile.

\section{Spectroscopic Characterization:}

The absorption spectrum in the range 200-900 nm of the solid Aeroxide ${ }^{\circledR} \mathrm{TiO}_{2}$ P25 has been determined (Fig.4) showing a moderated intensity absorption in the visible region above $400 \mathrm{~nm}$ and a consistent absorption in the region comprised between 320 and $400 \mathrm{~nm}$ wavelength (UVA)

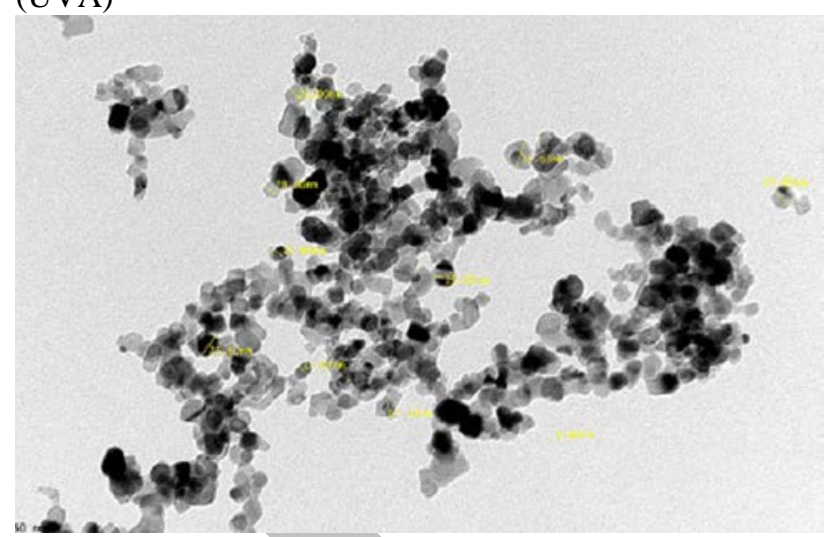

Figure 2: showing TEM image demonstrating the average particle size of Aeroxide ${ }^{\circledR} \mathrm{TiO}_{2} \mathrm{P} 25$ nanoparticles.

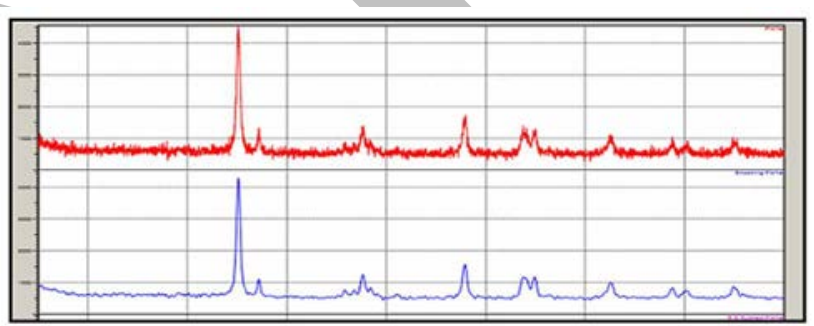

Figure 3: showing XRD patterns of as-purchased ( in blue) and standard Aeroxide ${ }^{\circledR} \mathrm{TiO}_{2}$ P25 nanoparticles (in red).

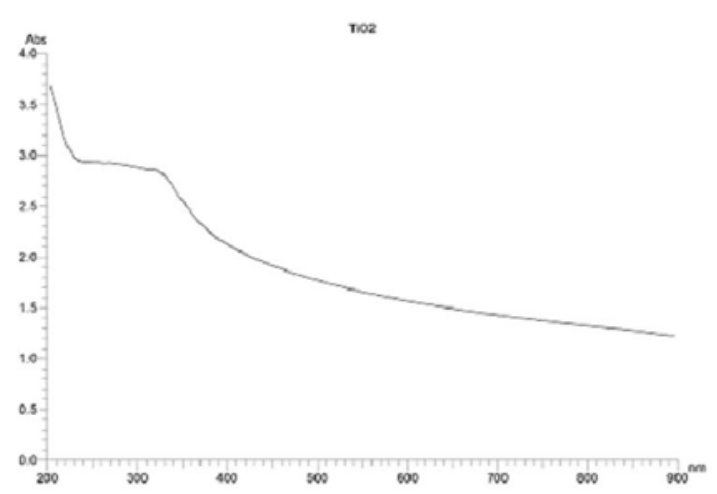

Figure 4: showing the solid-state diffusion-reflectance UV-Vis spectrum of Aeroxide ${ }^{\circledR} \mathrm{TiO}_{2} \mathrm{P} 25$.

\section{Methylene blue degradation efficiency:}

The means values of optical density of MB of all studied treatments measured at increasing time periods of UVA irradiation are shown graphically in (Fig. 5 ). There was a significant decrease $(\mathrm{P}<0.05)$ in the optical density of $\mathrm{MB}$ photodegraded by $\mathrm{P} 25$ after 1 hour of UVA radiation where the percentage decrease was equal to $54 \%$. There was no significant difference ( $\mathrm{p}>0.05)$ in the optical density of MB after 15, 30 and 45 min of UVA irradiation.

\section{Direct Contact Method:}

The mean values of optical density of candida albicans of all studied treatments measured at increasing time periods of UVA irradiation are shown graphically in (Fig.6). Data for OD values of candida albicans solution showed 
significant decrease $(\mathrm{P}<0: 05)$ for the P25 group after 60, 90 and 120 min of UVA exposure. The OD value after $2 \mathrm{~h}$ of direct contact between P25 and candida albicans under UVA light reached the minimum value $(0.0075)$ when compared with the optical density of candida of the control group (0.0318). There was no significant difference $(p>$ 0.05 ) in the optical density of Candida albicans after $30 \mathrm{~min}$ of UVA irradiation. Also, as shown in (Fig. 6), Only a slight decrease (statistically not significant) was evidenced in the OD values in the light treatments compared with control in the dark treatment and with $\mathrm{TiO}_{2}$ combined with light treatment.

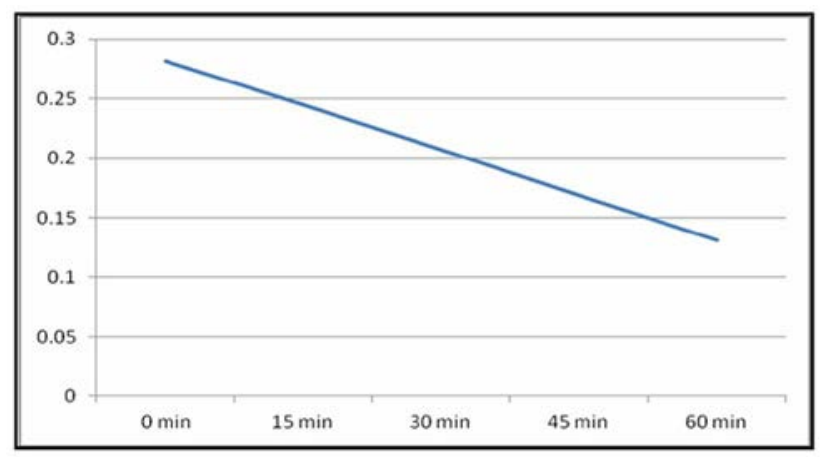

Figure 5: showing optical density of methylene blue solution photodegraded by $\mathrm{TiO}_{2}$ P25 after follow up periods up to 90 minutes.

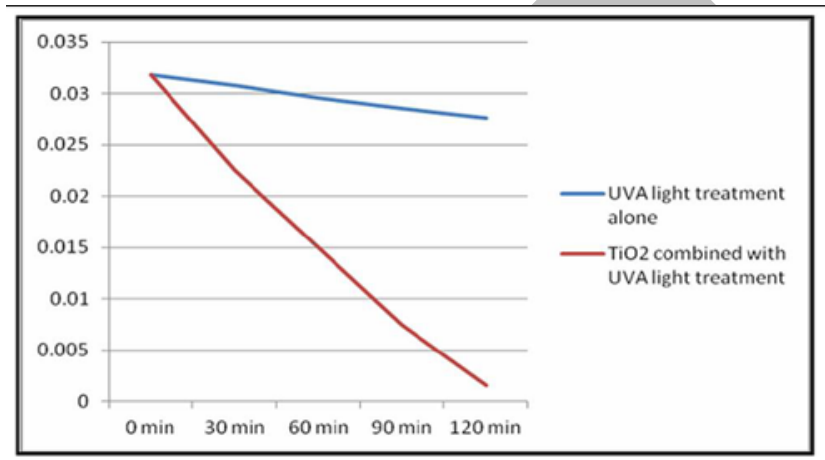

Figure 6: showing comparison between different studied treatments of candida albicans solution regarding optical density after follow up periods up to 120 minutes.

\section{Specimens testing:}

\section{Scanning Laser Microscopic Examination:}

Scanning Laser microscopic imaging revealed that the $2 \%$, $4 \%$ and $6 \%(\mathrm{w} / \mathrm{w})$ of nano-titanium concentrations were evenly distributed throughout the silicone elastomer specimens. Nano-titanium aggregates were detected as the nano-titania loading was increased to $8 \%$ and $10 \%(\mathrm{w} / \mathrm{w})$.

\section{Impregnated Culture Method:}

The percentages of reduction in CFUs/ml of candida albicans measured at increasing time periods of UVA irradiation are shown in (Table.1). The photocatalytic antifungal activity of silicone elastomer containing nanoparticles, at five concentrations (2\%, 4\%, 6\%, $8 \%$ and $10 \%)(w / w)$ of $\mathrm{SE} / \mathrm{TiO}_{2}$, against candida albicans was timedependent, such that extending the length of nanoparticles exposure to UVA from 30 to $120 \mathrm{~min}$ enhanced the inhibitory effects of nanoparticles on candida.

Data for CFUs values of candida albicans solution showed that in general, the photocatalytic antifungal activity of $\mathrm{SE} / \mathrm{TiO}_{2}$ was significantly higher than the activity of the control group without $\mathrm{TiO}_{2}$ in the dark $(\mathrm{P}<$ 0.05) and UVA illiumunation alone after a 90 and 120 min as shown in (Table.1). The differences between the antifungal effects of samples containing $2 \%(\mathrm{w} / \mathrm{w})$ nano$\mathrm{TiO}_{2}$ after 90 and 120 min versus those with silicone elastomer alone in the dark and UVA illumination alone were statistically significant $(P<0.05)$. Although $60 \mathrm{~min}$ time point showed reductions in the viability of candida albicans treated with $2 \%, 4 \%$ and $6 \%(w / w) ~ S E / \mathrm{TiO}_{2}$ under UVA treatment, these reductions were not significant $(P>$ $0.05)$ On the other hand, $8 \%$ and $10 \% \quad(\mathrm{w} / \mathrm{w})$ $\mathrm{SE} / \mathrm{TiO}_{2}$ under 60 min UVA illumination significantly reduced candida albicans viability.

Table 1: showing comparison between overall percentages decrease value of candida albicans of the six different studied groups under UVA light.

\begin{tabular}{|l|l|l|l|l|l|l|}
\hline $\begin{array}{l}\text { Time } \\
\text { interv } \\
\text { al } \\
\text { (min) }\end{array}$ & \multicolumn{6}{l}{$\begin{array}{l}\text { Percentage of candida albicans reduction of silicone } \\
\text { elastomer containing different percentage (w/w) } \\
\mathrm{TiO}_{2}\end{array}$} \\
\cline { 2 - 7 } & $\begin{array}{l}\text { Grou } \\
\text { p I }\end{array}$ & $\begin{array}{l}\text { Group } \\
\text { II }\end{array}$ & $\begin{array}{l}\text { Group } \\
\text { III }\end{array}$ & $\begin{array}{l}\text { Group } \\
\text { IV }\end{array}$ & $\begin{array}{l}\text { Group } \\
\text { V }\end{array}$ & $\begin{array}{l}\text { Group } \\
\text { VI }\end{array}$ \\
\hline 30 & 4 & 12 & 18 & 24 & 27 & 29 \\
\hline 60 & 7 & 36 & 41 & 47 & $50^{*}$ & $53^{*}$ \\
\hline 90 & 10 & $59^{*}$ & $65^{*}$ & $71^{*}$ & $74^{*}$ & $76^{*}$ \\
\hline 120 & 13 & $82^{*}$ & $87^{*}$ & $94^{*}$ & $97^{*}$ & $99.9^{*}$ \\
\hline
\end{tabular}

The CFUs/ml value reached the minimum value $(0.3$ $\left.\mathrm{x} 10^{(2)}\right)$ after $2 \mathrm{~h}$ of impregnation of silicone elastomer disc containing $10 \%(\mathrm{w} / \mathrm{w})$ of SE/P25 in candida albicans aqueous solution under UVA light when compared with the CFUs of the control group $\left(1.37 \times 10^{(5)}\right)$. There was no significant difference $(p>0.05)$ in the CFUs values of Candida albicans after 30 min of follow up.

Also as shown, Only a slight decrease (statistically not significant) was evidenced in the CFUs values in the light treatments compared with control in the dark treatment and with $\mathrm{SE} / \mathrm{TiO}_{2}$ combined with light treatment.

\section{DISCUSSION}

The importance of Silicone elastomer (SE) in dentistry is evident. They are widely used in fabricating facial prosthesis since 50 years ago (7). However one of the major problems that patients and maxillofacial prosthodontists commonly faced using these facial appliances is their potential for microbial biofilm formation due to surface texture, hydrophobicity and lack of antimicrobial property of silicone influence, which in turn increase microbial activity of pathogenic skin flora, especially Candida species, and in particular candida albicans $(2,4)$.

Upon accumulation of Candida in the unique microenvironment between facial prosthesis and the skin, the consequences will be a strong immunological reaction develops and dermatitis of the prosthesis-covered skin area occurs (29). In addition, significantly a disseminated fungal infections for elderly patients. Not only, but probably also, they penetrate into the material, deteriorating color and properties of the prosthetic material (30), which are thought to be the major factors limiting the longevity of facial prostheses (8).

It has been shown that mechanical cleaning methods are ineffective in complete eradication of microorganisms on facial prosthesis (11) particularly with the significant 
hygiene problems associated with aged hosts. In addition, chemical disinfecting agents are with the sideffects of converting to harmful products (10). Also, the significantly enhanced resistance of candida biofilm cells to antimicrobial agents, making eradication difficult (31).

Many researchers investigated the modification of the silicone elastomer using variety of surfactant formulations, increasing wettability of silicone surface and therefore reducing microbial adsorption, but unfortunately most of them show deterioration of silicone properties due to water sorption (32). Moreover incorporating conventional antimicrobial drugs such as antifungal / antibiotics into silicone have its own sideffects including drug resistance (12).

Nowadays, antimicrobial properties of nano-particles have attracted attention as a new strategy. Accordingly, many researches have been devoted to add antimicrobial nanoparticles (NP) to SE materials.

Efforts to add photocatalytic $\mathrm{TiO}_{2}$ NP have attracted much attention. $\mathrm{TiO}_{2}$ is such an inorganic nanoparticles, a white powder, which is a photocatalyst that is activated mainly by UV radiation to produce wide, fast and long-lasting antimicrobial efficacy, that can be used as a self cleansing agent (23). In addition to its unique features including chemical and physical stability, biocompatibility, odour free, availability and low cost; it would be an appropriate substance that can be incorporated into the dental materials (19). However, the antifungal effect of silicone elastomer containing $\mathrm{TiO}_{2}$ remains unclear.

XRD patterns of the as-purchased Aeroxide $\mathrm{TiO}_{2} \mathrm{P} 25$ (15\% Rutile \& 85\% anatase phase) confirmed the respective phases of $\mathrm{TiO}_{2}$. The morphologic characterization of $\mathrm{TiO}_{2}$ nanoparticles as observed by transmission electron microscopy \& scanning electron microscopic images were $22 \mathrm{~nm}$ and irregular faceted in particle size and shape respectively. Since the $\mathrm{P} 25$ form of $\mathrm{TiO}_{2}$ showed photocatalytic ability to degrade methylene blue dye and the obtained UV-Vis absorption spectrum range from 320 to $400 \mathrm{~nm}$ wavelength were consistent with the previous work which was the required form in our work, we continued the use of P25 form in our work.

Investigators have suggested incorporation of $\mathrm{TiO}_{2}$ photocatalyst nanoparticles within material itself and also coating on surface (14). The benefit of coating of $\mathrm{TiO}_{2}$ on the material surface drastically reduces the active micropores sites available that may serve as a reservoir of fungi. At the same time, the incorporation of $\mathrm{TiO}_{2}$ within the material itself allows constant presence of photocatalyst even if the SE material wears off. On the other hand, incorporation of NP causes these particles to agglomerate and aggregate. Agglomeration of the particles is a big problem that manifests during the preparation of nanocomposites, which in turn impacts diffusion of electron and adversely affect the antimicrobial properties of the polymerized material (18). It is noteworthy that the content of $\mathrm{TiO}_{2} \mathrm{NP}$ is of critical importance as it adversely affects degree of dispersion of nano additives in silicone elastomer matrix. Scanning laser microscopic examination of modified silicone elastomer materials to which $\mathrm{TiO}_{2} \mathrm{NP}$ added, indicated that all nanosized oxides distribute evenly throughout the silicone specimens, except for the $8 \%$ \& $10 \%(w / w)$ groups, which are partly agglomerated. Our findings suggested that with incorporation of nano- $\mathrm{TiO}_{2}$ at concentrations of $2 \%$ to $10 \%$ by weight into SE proportionally affected the antimicrobial properties of the polymerized material and antifungal rate values are improving with increase in concentration of $\mathrm{TiO}_{2}$. Also, when the concentration of nano- $\mathrm{TiO}_{2}$ is within the range of $8 \%-10 \%(\mathrm{w} / \mathrm{w})$, the antifungal ability is up to the maximum.

Many efforts have been made to achieve a uniform dispersion state. The most important and widely studied dispersion methods to prohibit association of small particles include calendering, sonication, and mechanical stirring (33). In order to attain a homogenous dispersion of the nanoparticles within silicone elastomer matrix by mechanical mixing using magnetic stirring, the use of a thining agent is necessary, which complicates the manufacturing procedure and may impair the physical and mechanical properties of silicone elastomer (34). Therefore the use of a more powerful mechanical stirring than magnetic ones together with the bulk reduction of the nanoparticles is preferred in the production of polymer matrix nano-composites to handle with such a highly viscous silicone elastomer. It has been also claimed that preparation of $\mathrm{TiO}_{2}$ nanometer photocatalyst by a hydrothermal method could partly inhibit the agglomeration of $\mathrm{TiO}_{2}$. Thus, the dispersion of nanoparticles was improved, optimizing the antimicrobial properties (35).

In accordance with our results, The research conducted by Lin et al. (17) reported that higher antimicrobial ability has been resulted in nano- $\mathrm{TiO}_{2} /$ rubber composites with bad dispersion state than those nanocomposites without agglomerations. Lin et al. (17) explained that in finer dispersion, the interfacial interactions between $\mathrm{TiO}_{2}$ and rubber matrix are strong, resulting in impeding effect against diffusion of electron subsequent reactions. While poor dispersion of nano- $\mathrm{TiO}_{2}$ generally means relatively weak interfacial interactions between $\mathrm{TiO}_{2}$ and rubber matrix, which facilitates diffusion of electrons in the composite.

The specimens were tested for inhibitory effect at time intervals of 30, 60, 90, and 120 minutes. Exposure of the specimens to UVA light was done during these time intervals. The source of UVA light was blacklight lamp of $15 \mathrm{~W}$ and highest emission at wavelength of $368 \mathrm{~nm}$. Our results also demonstrated that a significant increase in the antifungal rates was observed for candida albicans in silicone elastomer specimens containing $10 \%$ of nano- $\mathrm{TiO}_{2}$, exposed to UVA for $120 \mathrm{~min}$. On the other hand with no nanoparticles in the control group, UVA does not show any significant antimicrobial activity. That means, although UVA could reduce the Candida albicans population, utilizing $\mathrm{TiO}_{2}$ nanoparticles with UVA would significantly enhance that antifungal activity. This is consistent with the findings of other investigations as $\mathrm{Li}$ et al (16), and considered due to the to the formation of reactive oxygen species with UVA.

The results of this study also show that the antifungal activities of nanoparticles increased with time of irradiation because the last follow-up (after $120 \mathrm{~min}$ ) demonstrated the highest reduction in CFUs of candida. According to Fujishima et al.(36) that a higher intensity of UVA leads to higher photocatalytic activity of nanoparticles and more reactive oxygen species formed. As claimed by Choi et al.(20), the dynamics of the photo-killing process of 
microorganisms on orthodontic wires coated with $\mathrm{TiO}_{2}$ nanoparticles followed a pseudo-first-order kinetics or two-log inactivation pattern, as a first phase of high antimicrobial activity rate induced, followed by a steady plateau of antimicrobial activity rate at 20-30 min exposure to UVA, after which a reduction of antimicrobial rate phase ensured. That pattern was also reported by Watts et al.(32) while other reports showed two-step dynamics of photokilling process as reported by Sunada et al. (22) The latter pattern consisting of a step of a very low-rate antimicrobial activity followed by a higher rate one. However, in the present study, a steady increase in the antifungal rate in the SEs containing $\mathrm{TiO}_{2}$ nanoparticles was observed up to the last follow-up (after $120 \mathrm{~min}$ ). Thus, a longer follow-up is needed to detect at what time the inhibition trend reaches a plateau.

Based on these theories, it can be claimed that the time necessary to kill the germs was longer in some studies than that reported in others. This can be explained by the differences in the germ resistance. In other words, some microorganisms exhibited more sensitivity to the antimicrobial effects of the nanoparticles than others. Several reports have been proposed for the photo-killing mechanism of $\mathrm{TiO}_{2}$ under UV irradiation. For example, Blake et al (37) reported photocatalysis of microorganisms by $\mathrm{TiO}_{2}$ was in the order of virus $>$ bacterial cell $>$ bacterial spore and concluded that the order was mainly determined by microorganism type, in particular, cell wall thickness. Another report, Kuhn et al.(38) concluded that the antibacterial effects of $\mathrm{TiO}_{2}$ is in the order of Escherichia coli $>$ Pseudomonas aeruginosa $>$ Staphylococcus aureus $>$ Enterococcus faecium > Candida albicans and attributed that order mainly to the different thickness and complexity of the cell walls of the microorganism.

However, Haghighi et al. (29) found that despite yeast cells of C. albicans are more resistant than bacteria due to their thick cell wall consist of glucan and chitin, $\mathrm{TiO}_{2}$ nanoparticles had effective antifungal properties against it in comparison to fluconazole as potent antifungal drug. It was suggested that direct photocatalytic effect of $\mathrm{TiO}_{2}$ nanoparticles produce reactive oxygen species (ROS) that induce oxidation of intra cellular Coenzyme A or preoxidation of the membrane phospholipids which decrease respiratory activity and subsequently cause death cell (29).

The photocatalytic effect of $\mathrm{TiO}_{2}$ can be enhanced by several ways thus higher microbicidal effect can be achieved. It has been reported that preparation of $\mathrm{TiO}_{2}$ nanoparticles by a hydrothermal method leads to production of anatase phase which has higher photo catalytic activity than rutile-type (39). However the most photo catalytic activity has been reported when the two phases are mixed with the proportion of $80 \%$ anatase plus $20 \%$ rutile as in Aeroxide $\mathrm{TiO}_{2}$ P25 (Sigma aldrich Inc., USA) utilized in the present study (40).

Not to be lost in this discussion is the effect of $\mathrm{TiO}_{2}$ modification on the mechanical properties of the final product. It is well known that increasing concentrations of nanoparticles means higher photocatalytic and microbicidal activity but that does not necessarily means higher mechanical properties. As can be seen in wanga et al. (34) study. In order to enhance photocatalytic activity of the $\mathrm{TiO}_{2}$ without increasing the concentration of nano-particles, an appropriate source of UVA irradiation should be applied.
Taking the advantages of UVA as the patients should be instructed to keep their facial prosthetic appliances containing nano- $\mathrm{TiO}_{2}$ for about 3 min to 5 min in outdoors under sun exposure between 9.30 am to 11 am and 2 pm to $3.30 \mathrm{pm}$ when incidental UVB and infrared rays responsible for heat are less or for about $2 \mathrm{~h}$ under UVA lamps with an intensity of $1 \mathrm{~mW} / \mathrm{cm}^{2}$ during the night.

Thus, if these instructions are followed, there will be lesser microbial load in the facial prosthesis, hoping to preserve the facial prostheses from microbial deteriorations, increasing its longevity and decreasing the number of hospital visits have been made previously to remake the damaged prosthesis, lowering costs on society, and also protecting the patient from any dangerous biofilm induced local and systemic disorders and subsequently a better quality of life ensured.

A limitation of this study is that just one brand of $\mathrm{TiO}_{2}$ nanoparticles was applied. As previously reported by Lin et al (17) adding $\mathrm{TiO}_{2}$ nanoparticles from two different manufacturer to rubber, the results were conflicting no similar trends in antimicrobial values of the two types of $\mathrm{TiO}_{2}$ were observed as the concentration of NP were increased. However, the result of the current study, concur with Wang et al.'s (18), although the applied $\mathrm{TiO}_{2}$ were not identical in these two investigations. Moreover, defeated microorganisms were not similar, staphylococcus aureus in Wang et al. (18) and Candida albicans in ours.

Also we could not achieve our goal in testing the specimens under visible light, in the dark and for longer duration of exposure to UVA to confirm the photokilling activity of $\mathrm{TiO}_{2}$ in the nanocomposite. Moreover, in light of the importance of the effect of aging on the properties of silicone elastomer material containing nanoparticles, the lack of retesting the specimens after accelerated aging to evaluate the effect of nanoparticles after some time-interval, can be a limitation in this study. To address this issue, further studies should be considered.

\section{CONCLUSIONS}

Within the limitations of this study, it could be concluded that:

1- Scanning laser microscopy images showed adequate dispersion of nanoparticles in silicone elastomer in $2 \%, 4 \%$, $6 \%(\mathrm{w} / \mathrm{w})$ concentrations.

2- The incorporation of Aeroxide Titanium dioxide P25 nanoparticles to silicone elastomer MED-4210 can impart efficient antifungal activity to the silicone elastomer against candida albicans under UVA exposure, owing to the photocatalytic properties of nano- $\mathrm{TiO}_{2}$.

3- The antifungal rates increased with increasing concentrations of Titanium dioxide nanoparticles up to 10 $\mathrm{wt} \%$.

4- $6 \mathrm{wt} \%$ of $\mathrm{TiO}_{2}$ nanoparticles was considered, for economic reasons to the end user and less effect on the mechanical properties of silicone elastomer.

\section{CONFLICT OF INTEREST}

The authors declare that they have no conflicts of interest. 


\section{REFERENCES}

1. The Academy of prosthodontics. The glossary of prosthodontic terms $8^{\text {th }}$ ed. J Prosthet Dent. 2005; 94:10-92.

2. Ariani N, Vissink A, Van Oort RP, Kusdhany L, Djais A, Rahardjo TB, Van der Mei HC, Krom BP. Microbial biofilms on facial prostheses. Biofouling. 2012; 28:583-91.

3. Lemon JC, Kiat-Amnuay S, Gettleman L, Martin JW, Chambers MS. Facial prosthetic rehabilitation: preprosthetic surgical techniques and biomaterials. Curr Opin Otolaryngol Head Neck Surg. 2005; 13:255-262.

4. Veres EM, Wolfaardt JF, Becker PJ. An evaluation of the surface characteristics of a facial prosthetic elastomer. Part II: The surface texture. J Prosthet Dent. 1990; 63:325-331.

5. Kurtulmus H, Kumbuloglu O, Ozcan M, Ozdemir G, Vural C. Candida albicans adherence on silicone elastomers: Effect of polymerisation duration and exposure to simulated saliva and nasal secretion. Dental Materials. 2010; 26:76-82.

6. Haug SP, Moore BK, Andres CJ. Color stability and colorant effect on maxillofacial elastomers. Part II: weathering effect on physical properties. J Prosthet Dent. 1999; 81:423-30.

7. Ariani N, Visser A, van Oort RP, Kusdhany L, Rahardjo TB, Kromm BP, Van der Mei HC, Vissink A. Current state of craniofacial prosthetic rehabilitation. Int J Prosthodont. 2015; 26:57-67.

8. Visser A, Raghoebar GM, Van Oort RP, Vissink A. Fate of implant-retained craniofacial prostheses: life span and aftercare. Int J Oral Maxillofac Implants. 2008; 23:89-98.

9. Karakoca S, Aydin C, Yilmaz H, Bal BT. Retrospective study of treatment outcomes with implant-retained extraoral prostheses: survival rates and prosthetic complications. J Prosthet Dent. 2010; 103:118-26.

10. Eleni PN, Krokida MK, Polyzois GL, Gettleman L. Effect of different disinfecting procedures on the hardness and color stability of two maxillofacial elastomers over time. J Appl Oral Sci. 2013; 21:278-283.

11. Barnabe W, De Mendonca NT, Pimenta FC, Pegoraro LF, Scolaro JM. Efficacy of sodium hypochlorite and coconut soap used as disinfecting agents in the reduction of denture stomatitis, Streptococcus mutans and Candida albicans. J Oral Rehabil. 2004; 31:453-459.

12. Pigno MA, Goldschmidt MC, Lemon JC. The efficacy of antifungal agents incorporated into a facial prosthetic silicone elastomer. J Prosthet Dent. 1994; 71:295-300.

13. Beyth N, Houri-Haddad Y, Domb A, Khan W, Hazan R. Alternative Antimicrobial Approach: Nano-Antimicrobial Materials. Evid Based Complement Alternat Med. 2015;2015:246012.

14. Akiba N, Hayakawa I, Keh En-S, Watanabe A. Antifungal Effects of a Tissue Conditioner Coating Agent with $\mathrm{TiO}_{2}$ Photocatalyst. J Med Dent Sci. 2005; 52:223-227.

15. Sodagar A, Khalil S, Kassaee MZ, Shahroudi AS, Pourakbari B, Bahador A. Antimicrobial properties of poly (methyl methacrylate) acrylic resins incorporated with silicon dioxide and titanium dioxide nanoparticles on cariogenic bacteria. J Orthodont Sci. 2016; 5:7-13.

16. Li B, Zhao YM, Yang JC, Han Y, Dong ZW. Effect of Candida albicans growth on silicone elastomer containing nano- $\mathrm{TiO}_{2}$. Zhonghua Kou Qiang $\mathrm{Yi}$ Xue $\mathrm{Za}$ Zhi. 2008;43:367-9.
17. Lin G, Tian M, Lu YL, Zhang XJ, Zhang LQ. Morphology, Antimicrobial and Mechanical Properties of Nano- $\mathrm{TiO}_{2} /$ Rubber Composites Prepared by Direct Blending. Polymer Journal. 2006; 38:498-502.

18. Wang LL, Sun T, Zhou SY, Shao LQ. The Antibacterial Activities of Ag/Nano-TiO 2 Modified Silicone Elastomer. Acta Physica Polonica A. 2014; 2:125-248

19. Pal KS, Ranganath LM, Gaikwad AV, Sarapur S, Jain SK. Nanoparticles in Prosthodontics -boon or bane Review Paper. Journal of Oral Care and Research . 2015; 3:32-39.

20. Choi JY, Kim KH, Choy KC, Oh KT, Kim KN. Photocatalytic antibacterial effect of $\mathrm{TiO}_{2}$ film formed on $\mathrm{Ti}$ and TiAg exposed to Lactobacillus acidophilus. J Biomed Mater Res B Appl Biomater. 2007; 80:353-9.

21. Sunada K, Watanabe $T$, Hashimoto K. Studies on photokilling of bacteria on $\mathrm{TiO}_{2}$ thin film. J Photochem Photobiol A: Chemistry. 2003; 156:227-233.

22. Kubo Y, Ochi M, Sawada N, et al. Antifungal Effect of titanium dioxide photocatalysis on Candida albicans. JJpn Dent Products. 2001; 15:16-21.

23. Wang RM, Wang BY, He YF, Lv WH, Wang JF. Preparation of composited Nano- $\mathrm{TiO}_{2}$ and its application on antimicrobial and self-cleaning coatings. Polym Adv Technol. 2010;21:331-6.

24. Skocaj M, Filipic M, Petkovic J, Novak S. Titanium dioxide in our everyday life; is it safe? Radiol Oncol. 2011;45:227-47.

25. Al-Askari KS, Ariffin Z, Husein A, Reza F. Comparison of Microbial Adherence to Silicone Elastomers for MaxilloFacial Prostheses. World J. Med. Sci . 2014; 11:161-165.

26. Martins NCT, Ângeloa J, Girãob AV, Trindadeb T, Andradea L, Mendesa A. N-doped carbon quantum dots/TiO2 composite with improved photocatalytic activity. Appl Catalysis B Environ 2016;193:67-74.

27. AL Anbeaki RA, Hameed FR, Gassim FAG. Antifungal Activity of Titanum Dioxide Photocatalysis Against Fusarium oxysporum f.sp.lycopersici. Euphrates J Agric Sc 2009;1:14-26.

28. Zayed SMK. Effect of adding silicone dioxide nano particles on maxillofacial prosthesis silicone elastomer. Thesis submitted to department of prosthodontics faculty of dentistry- Alexandria University in fulfillment of the requirement for the degree of master science in removable prosthodontics 2012.

29. Haghighi F, Mohammadi SR, Mohammadi P, Hosseinkhani S, Shidpour R. Antifungal Activity of $\mathrm{TiO}_{2}$ nanoparticles and EDTA on Candida albicans Biofilms. Infect Epidemiol Med. 2013;1:33-8.

30. Taylor RL, Liauw CM, Maryan C. The effect of resin/crosslinker ratio on the mechanical properties and fungal deterioration of a maxillofacial silicone elastomer. J Mater Sci Mater Med 2003;14:497-502.

31. Chandra J, Mukherjee PK, Leidich SD, Faddoul FF, Hoyer LL, Douglas LJ, et al. Antifungal resistance of candidal biofilms formed on denture acrylic in vitro. J Dent Res. 2001;80:903-8.

32. Waters $M$, Jagger $R$. Improved wettability of an experimental silicone rubber denture soft lining material. J Biomed Mater Res. 1999;48:765-71.

33. Atif R, Inam F. Reasons and remedies for the agglomeration of multilayered graphene and carbon nanotubes in polymers. J Nanotechnol. 2016;7:1174-96. 
34. Wanga L, Liu Q, Jing D, Zhou S, Shao L. Biomechanical properties of nano- $\mathrm{TiO}_{2}$ addition to a medical silicone elastomer: The effect of artificial ageing. J Dent 2014;42:475-83.

35. Zhu L, Meng Z, Ghosh T, Oh W. Enhanced Photocatalytic Efficiency of Nanoscale $\mathrm{NiS}_{2} / \mathrm{TiO}_{2}$ Catalysts Synthesized by Hydrothermal and Sol-gel Method. J Korean Ceram Soc. 2012;49:135-41.

36. Fujishima A, Rao TN, Tryk DA. Titanium dioxide photocatalysis. J Photochem Photobiol. 2000;1:1-21.

37. Blake DM, Maness P, Huang Z, Wolfrum EJ, Huang J. Application of the photocatalytic chemistry of titanium dioxide to disinfection and the killing of cancer cells. Separ Purif Methods.1999;28:1-50.

38. Kuhn KP, Cahberny IF, Massholder K, Stickler M, Benz VW, Sonntag H, Erdinger L. Disinfection of surfaces by photocatalytic oxidation with titanium dioxide and UVA light. Chemosphere. 2003;53:71-7.

39. Nian J, Teng H. Hydrothermal Synthesis of SingleCrystalline Anatase $\mathrm{TiO}_{2}$ Nanorods with Nanotubes as the Precursor. J Phys Chem B. 2006;110:4193-8.

40. Ohno T, Sarukawa K, Tokieda K, Matsumura M. Morphology of a $\mathrm{TiO}_{2}$ Photocatalyst (Degussa, P-25) Consisting of Anatase and Rutile Crystalline Phases. J Catal. 2001;203:82-6.

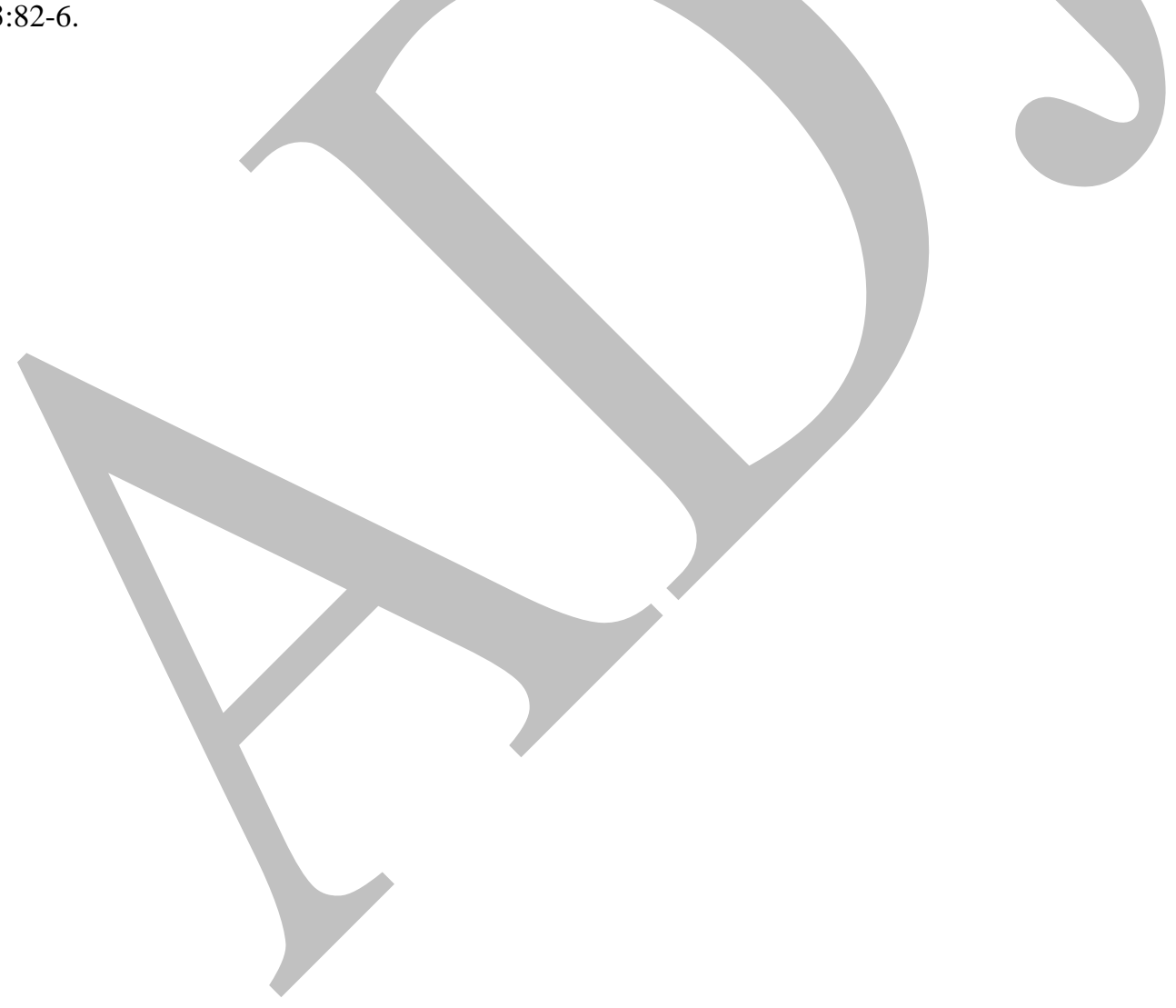

